\title{
Estimation of Technical Efficiency of Micro and Small-Scale Manufacturing Enterprises in Selected Towns of Jimma Zone, Oromia National Regional State
}

\author{
Haile Girma ${ }^{1}$, Gadisa Abera Dinka², Mohammedsani Ali Gelan² \\ ${ }^{1}$ Salale University, Ethiopia \\ 2Jimma University, Ethiopia \\ hghailove@gmail.com, aberagadisa@yahoo.com,mohammedsaniali22@gmail.com
}

\begin{abstract}
This study was conducted to estimate the technical efficiency of micro and small-scale manufacturing enterprises in Selected Towns of Jimma Zone, Oromia National Regional State by using the Stochastic Frontier Approach. The analysis used Cross-sectional data which was collected from 343 Micro and small-scale manufacturing enterprises in 2018. The finding shows the mean technical efficiency of sampled Micro and Small-Scale Manufacturing Enterprises is about $54.8 \%$ and output value-added is positively affected by capital input and raw material, but negatively affected by labor input. The finding from the inefficiency model indicates that technical inefficiency of sampled Micro and Small-Scale Manufacturing Enterprises is negatively affected by the amount of finance used for initial investment expenses; lower for enterprises which received land from the government, participate only in "Ekub", participate in both "Ekub" and "Edir". However, seasonal change in demand for a product is found to make technical inefficiency of enterprises higher. Thus, by improving Micro and Small-Scale Manufacturing Enterprises access to land, market, sufficient startup capital and strengthening social capital, it is possible to increase output valueadded.
\end{abstract}

Keywords: Technical Efficiency, Micro and Small-Scale, Manufacturing Enterprises.

\section{Introduction}

Micro and small-scale enterprises (MSEs) have paramount importance in the economy. MSEs are a great source of employment and income. They accelerate the rate of industrialization and economic growth. They also contribute to equity in income distribution and increase efficiency in low-income countries (Essien \& Yakub, 2007), (Donald \& Carl, 1998), (Hinderink \& Titus, 2002). The major development goals of the government of Ethiopia include: reducing poverty and unemployment, and economic transformation (industrialization). One of the strategies to achieve these goals is expanding MSEs since there is large potential of MSEs in the economy. But, the growth of performance of micro and small scale manufacturing industries has been poor and the implementation of large manufacturing projects has been delayed. These are the major reasons for the slow growth in the overall manufacturing sector of Ethiopia over the first growth and transformation plan periods (FDRE, 2016). The government of Ethiopia has tried to provide greater attention for micro and small enterprises development in last years. However, a few enterprises have been promoted to the next higher level. The reason is that greater focus was given to new establishments rather than supporting previously established ones. Besides, there is no clear separate strategy formulated for the establishment and development of SMEs even though improvements are witnessed. It is supposed that the current situation of MSMEs is seemingly continuing in the future (Amare \& A. Raghurama, 2017).

According to (EEA, 2015), the contribution of manufacturing SMEs in GDP has decreased from about 1.6 percent in 2004/05 to 1.3 percent in 2012/13 in the Ethiopian economy. The number of manufacturing SMEs is by far higher than that of large and medium scale manufacturing industries. However, their contribution to GDP is lower than large and medium scale manufacturing industries throughout the periods. The existing data shows that few SMEs have been graduating into medium-size enterprises and there are those closed down. As a result the number of SMEs operating and the number of employment opportunities created is not grown. In Ethiopia, the MSE sector generates huge employment opportunities next to agriculture. According to a National survey conducted by the Central Statistics Agency in 2007, the number of people engaged in this sector is greater than 1.3 million. However, a large number of MSEs has not been grown and remain to be survival type (CSA, 2007). Furthermore, as of (Gebreyesus, 2007), about 69\% of MSEs are found survival and as of (Wasihun \& Paul, 2010) about 75.6\% of the MSEs are unable to grow at all since start-up and only $21.9 \%$ of the MSEs had added workers. Thus, factors that influence the efficiency of manufacturing micro and smallscale enterprises should be identified and appropriate policy action should be recommended. These were the 
purposes of this study. The general objective of the study is to analyse the technical efficiency of micro and small-scale manufacturing enterprises in selected towns of Jimma Zone.

The specific objectives would be:

$\checkmark$ To find out the input-output relationship in micro and small-scale manufacturing enterprises.

$\checkmark$ To detect the demographic and socio-economic factors which influence the technical efficiency of micro and small-scale manufacturing enterprises?

\section{Literature Review}

The Concepts of Efficiency in Production: As of (William, 2008) production is defined as a method of transforming inputs to outputs. In the production process, a producer may be technically and/or allocatively efficient or inefficient. A producer is said to be efficient if as much as possible is produced with the inputs used or equal output is produced at possible minimum cost. Technical efficiency indicates the ratio of actual output to the optimal value as specified by a 'production function.' If the ratio is less than one, we say that the producer is technically inefficient. (Farrell, 1957) developed the first theoretical description of production technical efficiency. The producer's production efficiency can be measured by assessing a production frontier which envelops all inputs/outputs data used in the study.

Figure 1: Technical and Allocative Efficiency

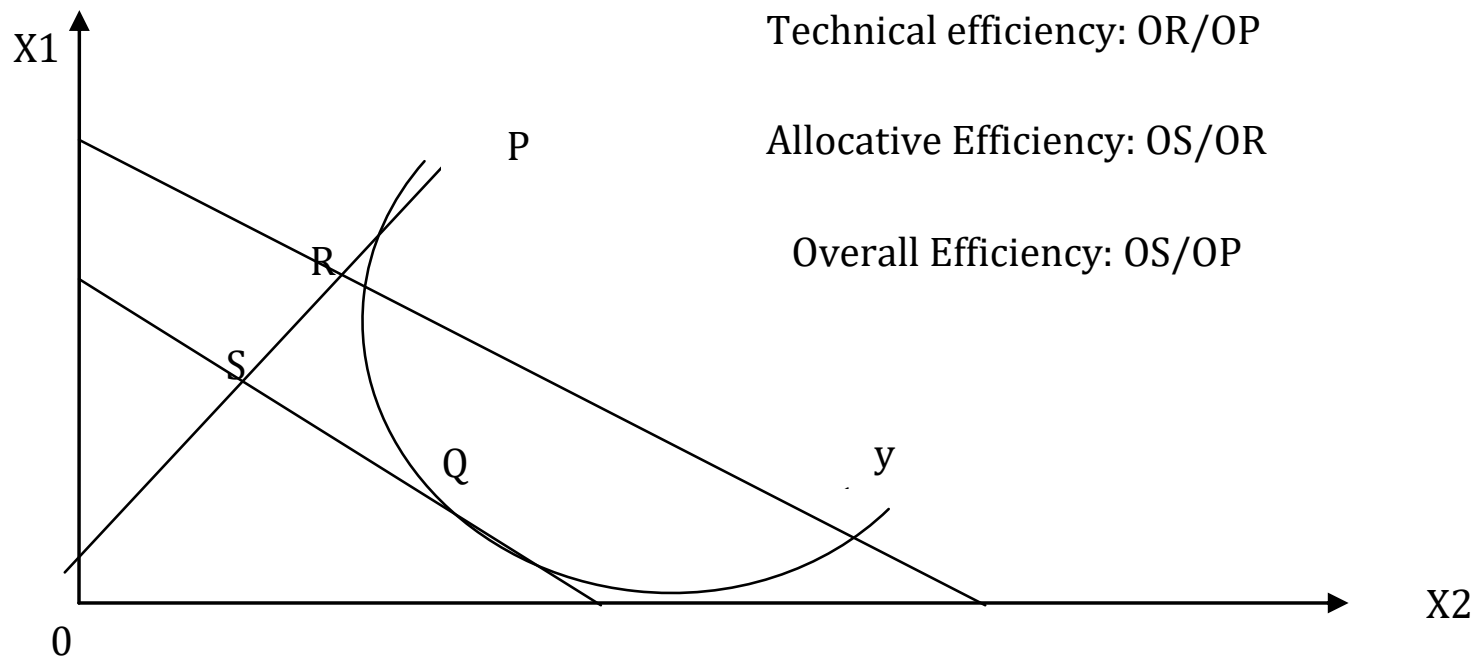

Figure 1 shows Farell's decomposition of overall efficiency into technical efficiency and allocative efficiency. Let us assume that single-output $(\mathrm{Y})$ is produced by using two inputs ( $\mathrm{x} 1 \& \mathrm{X} 2)$. Our production function will be $\mathrm{Y}=\mathrm{f}(\mathrm{X} 1, \mathrm{X} 2)$ and is linearly homogeneous. Any point on isoquant $\mathrm{Y}$ shows technically efficient combinations, but only point $Q$ indicates technical efficiency with minimum cost. Technical efficiency can be shown as OR/OP while allocative efficiency can be shown as OS/OR. The overall efficiency is the product of the two efficiencies (i.e. OS/OP).

Approaches to Measuring the Efficiency: Stochastic Frontier Analysis (SFA) and Data Envelopment Approach (DEA) are most applied approaches to measure efficiency. In this study, SFA is applied since it is a parametric approach which means that it follows a defined production function. Furthermore, the inefficiency term in composite error term of the function in the SFA model can be isolated from stochastic term (Coelli, 1996). One drawback of DEA is that it is a non-parametric and non-stochastic Approach which applies linear programming methodology to develop the efficient frontier. Another weakness of DEA is that it does not permit isolation of the stochastic noise from the inefficiency effect and it is also vulnerable to measurement errors and outliers (Erkoc, 2012), (Coelli, 1996).

Factors Affecting Efficiency: Many researchers have studied efficiency in production in the past however, the greatest number of previous researches. In the study of efficiency is related to the agriculture sector the study of technical efficiency related to Micro and small-scale manufacturing Enterprises is almost neglected 
particularly. However, Micro and small-scale manufacturing Enterprises have the greatest contribution in the economic development of Ethiopia and they are the base for current economic industrialization of the government's economic policy. As of (Berihu, 2014) Ethiopia has been giving greater focus for MSEs, development. This is because MSEs have a larger contribution to economic growth, employment generation and building an industrial economy in the country. This study is, therefore, conducted to identify factors hindering the growth and efficiency of micro and small-scale manufacturing enterprises and give policy recommendation so that the solution will contribute to the economic policy objective of the government previous researches indicate that various factors affect the technical efficiency of MSEs. Age of promoters, social networking, initial capital, vocational training and investment in ICT affects the efficiency of MSEs positively while business plan and enterprises' size affect the efficiency of MSEs negatively (Tekle, Sandraa \& Berhanu, 2016). The owner's age, level of education and training, and access to infrastructure affect efficiency positively while Sourcing start-up capital from financial institutions affects it negatively (Mosomi, 2011).

The efficiency of MSEs is also found to be affected by Managerial inefficiency in the optimal selection of resource (Gamachis, 2017). It is also found that the efficiency of MSEs is influenced positively by size, ownership, credit availability and employment of hired labour, but negatively by region (location) and nature of seasonality of operation (Rajesh Raj S N, 2007). As of (Zulridah \& Liew, 2014) Salary and wages per worker, research and development expenditure, training expenditures affect technical efficiency in microenterprises positively and significantly while the ratio of unskilled labour affects it negatively and significantly. Besides, (Igbekele, 2003) found that the efficiency of MSEs is positively influenced by Education, a number of employees, level of investment and age of business, but negatively by age of the operator. As discussed before the literature shows that various factors influence the level of technical efficiency of MSEs. However, some of the findings in these reviewed researches are conflicting. Some of the factors which are found to change the technical efficiency of MSEs positively in some literatures are reported in some other literatures to change it negatively. For instance, age (Tekle, Sandraa \& Berhanu, 2016), (Mosomi, 2011), (Igbekele, 2003); size (Tekle, Sandraa \& Berhanu, 2016), (Rajesh, 2007); credit (Mosomi, 2011), (Rajesh, 2007).

\section{Methodology of the Study}

Data Sources and Data Type: The researchers used primary data gathered from owners/managers of micro and small-scale enterprises of selected towns of Jimma Zone. Jimma zone was selected by convenient sampling technique since it is in the catchment area of Jimma University. The multistage sampling technique was used in the collection of required data for the studies i.e. at first woredas' Towns were selected from which owners/ managers were selected. Accordingly, Jimma, Agaro, Sokoru, and Asandabo were selected based on the consultation with the Food security and Employment creation officers, as well as trade and industry officers of Jimma zone and Jimma town. These towns have a higher number of micro and small-scale enterprises in the Zone. Then, the respondents were selected by random sampling technique from each town.

Sample Size Determination: To determine the sample size, the researchers used a sample frame collected from Jimma zone office of food security and job creation by using Cochran's formula (Cochran, 1977):

$n_{o}=\frac{Z^{2}}{e^{2}} p q$...

Where,

$n_{o}=$ sample size

$\mathrm{z}=$ critical value

$\mathrm{p}=$ estimated proportion of an attribute that is present in the population and $\mathrm{q}=1-\mathrm{p}$

$\mathrm{e}=$ level of precision.

For this study $\mathrm{p}=0.5$, thus $\mathrm{q}=1-0.5=0.5, \mathrm{z}=95 \%(0.95), \mathrm{e}=5 \%(0.05)$ was used. As a result, the sample size was found to be 384. Then, the sample size was allocated proportionately to the selected towns based on secondary data found from Jimma zone and Jimma town's food security and job creation, and trade and industry offices as shown in table 1 . As can be understood from this table the researchers proposed to collect data from the manager/operator of 384 enterprises. But, 11 questionnaires were not properly answered and 30 questionnaires were not distributed because the respondents were not willing to respond. It means that 
the response rate is $89.3 \%$. Thus, 343 questionnaires were used in the analysis the minimum and maximum initial investment expenses.

Table 1: Sample Size Allocation

\begin{tabular}{|c|c|c|c|c|}
\hline Town & $\begin{array}{l}\text { Enterprise } \\
\text { (ownership) }\end{array}$ & $\begin{array}{l}\text { Number of } \\
\text { Enterprises }\end{array}$ & $\begin{array}{l}\text { Sample } \\
\text { size/proposed } \\
\text { Respondents } \\
\end{array}$ & $\begin{array}{l}\text { Number of questionnaires } \\
\text { properly filled and } \\
\text { returned }\end{array}$ \\
\hline \multirow{4}{*}{ Jimma } & Proprietorship & 110 & $42 * 1$ & \\
\hline & Partnership & 692 & 265 & \\
\hline & Total & 802 & 307 & 281 \\
\hline & Proprietorship & 58 & 22 & \\
\hline \multirow[t]{2}{*}{ Agaro } & Partnership & 29 & 11 & \\
\hline & Total & 87 & 33 & 26 \\
\hline \multirow[t]{3}{*}{ Asandabo } & Proprietorship & 26 & 10 & \\
\hline & Partnership & 31 & 12 & \\
\hline & Total & 57 & $22-6$ & 17 \\
\hline \multirow[t]{3}{*}{ Sokoru } & Proprietorship & 35 & 13 & \\
\hline & Partnership & 22 & 9 & \\
\hline & Total & 57 & 22 & 19 \\
\hline Total & & 1,003 & 384 & 343 \\
\hline
\end{tabular}

Source: Computed from Jimma zone food security and job creation, and trade and industry offices', 2018

Method of Data Analysis: In this study, we used descriptive and inferential tools of data analysis. In descriptive analysis percentage and tabular presentations of statistical tools were employed. Under the econometric analysis, in the efficiency model, we employed a stochastic frontier model to estimate the level of technical efficiency of firms by using single step. The stochastic frontier model was estimated using STATA software version 13.

The following stochastic production function is used:

$Y_{i}=f\left(X_{i j} \beta\right) \exp \left(V_{i}-U_{j}\right)$

Where,

$Y_{i}=$ output of the $i^{\text {t回 }}$ enterprise

$X_{i}=$ vector of input quantities

$\beta=$ vector of unknown parameters

$V_{i}=$ symmetric error term

$U_{j}=$ inefficiency term which is non-negative

Technical efficiency (TE) $=\frac{Y_{i}}{Y_{i}^{*}}=f\left(X_{i}, \beta\right) \exp \left(V_{i}-U_{i}\right) / f\left(X_{i}, \beta\right) \exp \left(V_{i}\right) \ldots \ldots . .3 .2$

$=(\boldsymbol{e x p})\left(-U_{i}\right)$

Where,

$Y_{i}=$ observed output

$Y_{i}^{*}=$ Frontier output

Technical inefficiency relative to stochastic production frontier is captured by one-sided error component $\left(-U_{i}\right),(-\boldsymbol{U}) \geq \mathbf{0}$. ..3.4

The Model Estimated: The production technology of micro and small-scale enterprises in this study is assumed to be specified by the Cobb Douglas frontier production function as:

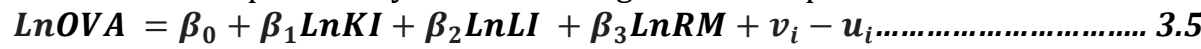

Where,

- $\quad$ Ln = natural logarithm

- OVA = output value added

$\circ \quad \mathrm{KI}=$ capital input

1 it is found by multiplying all by the factor $0.383(384 / 1003)$ 
$\circ \quad \mathrm{LI}=$ labor input

- $\mathrm{RM}=$ raw materials

- $\quad \beta^{\prime} \mathrm{s}=$ parameters to be estimated

- $v_{i}=$ random error

○ $u_{i}=$ non-negative random term

Technical Efficiency: The inefficiency function will be:

$T E\left(u_{i}\right)=\delta_{0}+\delta_{1}$ owners?ip $+\delta_{2} F$ Size $+\delta_{3}$ Entreage $+\delta_{4}$ Busiage $+\delta_{5} E d u c+$

$\delta_{6}$ SorInInvest $+\delta_{7}$ InitInvest $+\delta_{8}$ Busplan $+\delta_{9}$ Accesfinan $+\delta_{10}$ Availinfra $+\delta_{11}$ Training +

$\delta_{12}$ Locaenter $+\delta_{13}$ InvICT $+\delta_{14}$ SocNet $+\delta_{15}$ Seasonoper $+\delta_{16}$ Competition $+\delta_{17}$ Land +

$\epsilon_{i}$ 3.6

Where,

- $\quad$ ownership $=$ Types of ownership

- $\quad$ F Size $=$ Family size

- Entre age $=$ Entrepreneur age

- Busiage $=$ Age of business

- Educ=Level of education

- SorInInvest $=$ Source of initial investment

- InitInvest= Initial investment

- Bus plan= business plan

- Accesfinan= access to finance

- Availinfra= Availability of infrastructure

- Locaenter= location of the enterprises

- InvICT = investment on information Communication and Technology

- SocNet $=$ Social networking $/$ capital

- Seasonoper $=$ Seasonality of operation

- $\delta_{i}=$ Inefficiency parameters to be estimated.

- $\epsilon=$ random error

Table 2: Description of Variables

\begin{tabular}{|c|c|c|c|}
\hline & Variables & Description & Expected Sign \\
\hline \multirow{5}{*}{ 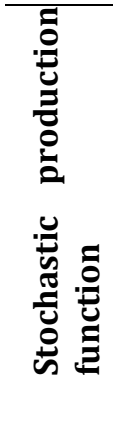 } & Output value added (OVA) & $\begin{array}{l}\text { It was calculated as total value of output } \\
\text { (sales revenue) minus the cost of raw } \\
\text { materials and indirect costs }\end{array}$ & \\
\hline & Capital input (KI) & $\begin{array}{l}\text { Firms' capital stock (Ki) is measured as the } \\
\text { replacement value }\end{array}$ & positive \\
\hline & Labor input (LI) & Total number of workers in the Enterprise & positive \\
\hline & Raw materials (RM) & $\begin{array}{l}\text { costs of materials and energy which is a } \\
\text { proxy of raw materials used by enterprises }\end{array}$ & positive \\
\hline & Types of ownership(ownership) & $\begin{array}{l}1 \text { if owned sole proprietor, } 0 \text { otherwise } \\
\text { (owned partnership, others) }\end{array}$ & positive \\
\hline \multirow{5}{*}{ 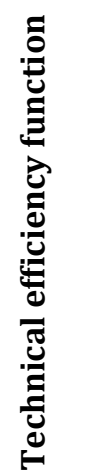 } & Family size (FSize) & $\begin{array}{l}\text { Number of family members of } \\
\text { owner/operator of the enterprise }\end{array}$ & positive \\
\hline & Entrepreneur age (Entreage) & $\begin{array}{l}\text { Age of business operator/decision-maker (in } \\
\text { years) }\end{array}$ & negative \\
\hline & Age of business (Busiage) & $\begin{array}{l}\text { Number of years of enterprise up to survey } \\
\text { year }\end{array}$ & negative \\
\hline & Level of education (Educ) & $\begin{array}{l}\text { Level of education of operator/decision- } \\
\text { maker (in years) }\end{array}$ & negative \\
\hline & $\begin{array}{l}\text { Source of the initial investment } \\
\text { (SorInInvest) }\end{array}$ & 1 if own self, 0 otherwise & negative \\
\hline
\end{tabular}




\begin{tabular}{|c|c|c|}
\hline Initial investment (InitInvest) & $\begin{array}{l}\text { The amount of money invested when the } \\
\text { enterprise starts its operation (in Birr) }\end{array}$ & negative \\
\hline business plan (Busplan) & $\begin{array}{l}1 \text { if the enterprise has a business plan, } 0 \\
\text { otherwise }\end{array}$ & negative \\
\hline access to finance (Accesfinan) & $\begin{array}{l}1 \text { if the enterprise has received credit during } \\
\text { its operation, } 0 \text { otherwise }\end{array}$ & negative \\
\hline Improve & $\begin{array}{l}1 \text { if the enterprise introduced improvement } \\
\text { to existing products in the previous five } \\
\text { years, } 0 \text { otherwise }\end{array}$ & negative \\
\hline $\begin{array}{l}\text { Availability of infrastructure } \\
\text { (Availinfra) }\end{array}$ & $\begin{array}{l}1 \text { if the enterprise easily accesses to } \\
\text { electricity, water, etc., } 0 \text { otherwise }\end{array}$ & tive \\
\hline Training & $\begin{array}{l}\text { Number of days the enterprise's } \\
\text { owner/operator trained }\end{array}$ & negative \\
\hline $\begin{array}{l}\text { location of the enterprises } \\
\text { (Locaenter) }\end{array}$ & $\begin{array}{l}1 \text { if the enterprise is near to the main road, } 0 \\
\text { otherwise }\end{array}$ & negative \\
\hline investment in ICT(InvICT) & $\begin{array}{l}1 \text { if the enterprise investment in ICT to } \\
\text { promote its sale, } 0 \text { otherwise }\end{array}$ & negative \\
\hline Social networking/capital (SocNet) & $\begin{array}{l}1 \text { if the enterprise participates in Ekub } \\
\text { (rotating saving) and develops social capital, } \\
0 \text { otherwise }\end{array}$ & negative \\
\hline $\begin{array}{l}\text { Seasonality } \\
\text { (Seasonoper) }\end{array}$ & $\begin{array}{l}1 \text { if the enterprise's product demand is non- } \\
\text { seasonal, } 0 \text { otherwise }\end{array}$ & negative \\
\hline Competition & $\begin{array}{l}1 \text { if the enterprise doesn't face competition, } \\
0 \text { otherwise }\end{array}$ & positive \\
\hline Land & $\begin{array}{l}1 \text { if the government provides land and } \\
\text { premise at start-up, } 0 \text { otherwise }\end{array}$ & negative \\
\hline
\end{tabular}

\section{Results and Discussion}

Descriptive Analysis: Table 3 shows results of continuous variables. The minimum and maximum age of operator of the enterprises is 21 years and 50 years respectively while the mean of age of the operator is about 31 years. The minimum and maximum size of the family of the operator of enterprises is 1 and 6 respectively while the mean is about 3 . The minimum and maximum years of education of the operator of enterprises are 5 years and 17 years respectively while the mean is about 3 years and half. The minimum and maximum years of enterprises since establishment to survey years are 1 year and 21 years respectively while the mean is about 2 years. The minimum and maximum initial investment expenses are Birr 5000 and 260,000 respectively while the mean is about Birr 73157. The minimum and maximum amount of capital input estimated as the value of equipment used in production are Birr 5000 and Birr 2500,000 respectively while the mean is about Birr 160438.5. The minimum and maximum amount of output-value added (estimated by the difference of sales revenue and costs of raw materials per month) are Birr 500 and Birr 90,000 respectively while the mean is about Birr 16,913. The minimum and maximum numbers of labors employed in the enterprises are 1 and 16 persons respectively while the mean is about 6 persons. The minimum and maximum monthly costs of raw materials used by the enterprise are Birr 500 and 95000 respectively while the mean is about Birr 25,342. The minimum and maximum days of training taken by the operator of enterprises are 0 and 14 while the mean is about 2 and half days. 
Table 3: Summary of Statistics of Continuous Variables

\begin{tabular}{llllll}
\hline Variable & Obs & Mean & Std. Dev. & Min & Max \\
\hline Entre age & 343 & 31.25 & 5.57 & 21 & 50 \\
Fsizeo & 343 & 2.70 & 1.39 & 1 & 6 \\
EduO & 343 & 12.29 & 2.48 & 5 & 17 \\
Busiage & 343 & 4.94 & 2.21 & 1 & 21 \\
InitInvest & 343 & 73157.73 & 54524.37 & 5000 & 260000 \\
KI & 343 & 160438.5 & 222634.1 & 5000 & 2500000 \\
OVA & 343 & 16913.41 & 13246.14 & 500 & 90000 \\
Currentemplo & 343 & 6.052478 & 2.392151 & 1 & 16 \\
RM & 343 & 25342.71 & 17837.4 & 500 & 95000 \\
Training & 343 & 2.437318 & 1.79701 & 0 & 14 \\
\hline
\end{tabular}

Source: Own computation from field survey, 2018

Table 4 shows results related to dummy variables. This table shows that most of the sampled operators of enterprises are males (60.06\%); are owned in partnership form (80.76\%); got finance for initial investment from other sources (56.27\%); didn't get land from government (66.18\%); easily access to infrastructure like road and electricity (90.38\%); have business plan (88.05\%); are near to main road (73.47\%); which didn't face competition (18027.68), which demand for their product is not seasonal (18323.15), which participate both in "Ekub" and "Edir" (19881.02), introduced major improvement to their product (99.42\%); faced competition (67.35\%); have seasonal demand for their product $(68.51 \%)$ and participate only in "Ekub" $(42.27 \%)$.

Table 4: Summary of Statistics of Dummy Variables

\begin{tabular}{|c|c|c|c|c|}
\hline Variable & Category & Frequency & Percent & Cumulative \\
\hline & Male & 206 & 60.06 & 60.06 \\
\hline \multirow[t]{3}{*}{ Sex 0} & Female & 137 & 39.94 & 100.00 \\
\hline & Total & 343 & 100.00 & \\
\hline & sole proprietor & 66 & 19.24 & 19.24 \\
\hline \multirow[t]{3}{*}{ Ownership } & Partnership & 277 & 80.76 & 100.00 \\
\hline & Total & 343 & 100.00 & \\
\hline & Otherwise & 193 & 56.27 & 56.27 \\
\hline \multirow[t]{3}{*}{ SorInInvest } & Own self & 150 & 43.73 & 100 \\
\hline & Total & 343 & 100 & \\
\hline & Otherwise & 227 & 66.18 & 66.18 \\
\hline \multirow[t]{3}{*}{ Land } & government land & 116 & 33.82 & 100 \\
\hline & Total & 343 & 100 & \\
\hline & Other wise & 33 & 9.62 & 9.62 \\
\hline \multirow[t]{3}{*}{ Availinfra } & easily access to electricity and water & 310 & 90.38 & 100 \\
\hline & Total & 343 & 100 & \\
\hline & Has no business plan & 41 & 11.95 & 11.95 \\
\hline \multirow[t]{3}{*}{ Busplan } & Has business plan & 302 & 88.05 & 100 \\
\hline & Total & 343 & 100 & \\
\hline & Not near to main road & 91 & 26.53 & 26.53 \\
\hline \multirow[t]{3}{*}{ Locaenter } & Near to main road & 252 & 73.47 & 100 \\
\hline & Total & 343 & 100 & \\
\hline & Not Introduced major improvement & 2 & 0.58 & 0.58 \\
\hline \multirow[t]{2}{*}{ Improve } & Introduced major improvement & 341 & 99.42 & 100 \\
\hline & Total & 343 & 100 & \\
\hline \multirow[t]{4}{*}{ Competition } & No competition & 112 & 32.65 & 32.65 \\
\hline & Faced competition & 231 & 67.35 & 100 \\
\hline & Total & 343 & 100 & \\
\hline & Demand for product is not seasonal & 108 & 31.49 & 31.49 \\
\hline \multirow[t]{2}{*}{ Seasonoper } & Demand for product is seasonal & 235 & 68.51 & 100 \\
\hline & Total & 343 & 100 & \\
\hline
\end{tabular}




\begin{tabular}{lllll}
\hline \multirow{3}{*}{ SocNet } & Not participate both in "edir" and "ekub" & 28 & 8.16 & 8.16 \\
& participate in "ekub" & 145 & 42.27 & 50.44 \\
& participate in "edir"| & 33 & 9.62 & 60.06 \\
& participate in both "ekub" \& "edir" & 137 & 39.94 & 100 \\
& Total & 343 & 100 & \\
\hline
\end{tabular}

Source: Own computation from survey data, 2018

Table 5 indicates the average amount of output value-added per enterprises across dummy variables. One can understand that the mean of output value-added is larger for female operators (17668.61), sole proprietorship (19272.73), those which got initial investment fund from other sources (18106.22), provided land by government (18841.38), easily access to infrastructure (17054.52), which have business plan (17023.64), which didn't access to credit (18356.16), which are near to main road (17104.37), which made major improvement in their product (16963.34), which didn't face competition (18027.68), which demand for their product is not seasonal (18323.15), which participate both in "Ekub" and "Edir" (19881.02). This validates that output among enterprises in the sample might vary as a result of technical inefficiency. On the other hand, the mean of output value-added is lower for male operators (16411.17), partnership (16411.17), those which got initial investment fund from their own sources (15378.67), not provided land by government (15928.19), didn't easily access to infrastructure (15587.88), which haven't business plan(16100), which access to credit (18356.16), which are not near to main road (16384.62), which didn't made major improvement in their product (8400), which faced competition (16373.16), which demand for their product is seasonal (16265.53), which participate neither in "Ekub" nor "Edir" (11967.86).

Table 5: Summary of Statistics of Dependent Variable across Dummy Variables

\begin{tabular}{|c|c|c|c|c|c|c|}
\hline \multirow[b]{2}{*}{$\begin{array}{l}\text { Dummy } \\
\text { Variables }\end{array}$} & & \multicolumn{4}{|c|}{ Dependent Variable: OVA } & \multirow[b]{2}{*}{$\operatorname{Max}$} \\
\hline & & Obs. & Mean & Std. Dev. & Min & \\
\hline \multirow{4}{*}{ SexO } & Male & 206 & 16411.17 & 14380.94 & 500 & 90000 \\
\hline & Female & 137 & 17668.61 & 11337.39 & 1500 & 80000 \\
\hline & Total & 343 & & & & \\
\hline & Partnership & 277 & 16351.26 & 13266.52 & 500 & 90000 \\
\hline \multirow[t]{3}{*}{ Ownership } & Sole proprietorship & 66 & 19272.73 & 12994.89 & 1500 & 80000 \\
\hline & Total & 343 & & & & \\
\hline & Other & 193 & 18106.22 & 14367.5 & 1300 & 90000 \\
\hline \multirow[t]{2}{*}{ SorInInvest } & Own & 150 & 15378.67 & 11511.86 & 500 & 78000 \\
\hline & Total & 343 & & & & \\
\hline \multirow[t]{4}{*}{ Land } & $\begin{array}{l}\text { Not provided by the } \\
\text { government }\end{array}$ & 227 & 15928.19 & 14103.24 & 1300 & 85000 \\
\hline & Provided by the government & 116 & 18841.38 & 11191.68 & 500 & 90000 \\
\hline & Total & 343 & & & & \\
\hline & Not easily access & 33 & 15587.88 & 18015.74 & 500 & 80000 \\
\hline \multirow[t]{2}{*}{ Availinfra } & Easily access & 310 & 17054.52 & 12664.09 & 800 & 90000 \\
\hline & Total & 343 & & & & \\
\hline \multirow[t]{3}{*}{ Busplan } & Has no business plan & 41 & 16100 & 16961.35 & 500 & 80000 \\
\hline & Has business plan & 302 & 17023.84 & 12689.64 & 12689.64 & 90000 \\
\hline & Total & 343 & & & & \\
\hline \multirow[t]{3}{*}{ Crdt } & Didn't Received credit & 73 & 18356.16 & 12018.04 & 500 & 78000 \\
\hline & Received credit & 270 & 16523.33 & 13553.58 & 1300 & 90000 \\
\hline & Total & 343 & & & & \\
\hline \multirow[t]{2}{*}{ Locaenter } & Not near to the main road & 91 & 16384.62 & 11645.63 & 500 & 78000 \\
\hline & $\begin{array}{l}\text { Near to main road } \\
\text { Total }\end{array}$ & 252 & 17104.37 & 13795.16 & 1300 & 90000 \\
\hline \multirow[t]{3}{*}{ Improve } & Not Major improvement & 2 & 8400 & 5515.433 & 4500 & 12300 \\
\hline & Major improvement & 341 & 16963.34 & 13265.52 & 500 & 90000 \\
\hline & Total & 343 & & & & \\
\hline
\end{tabular}




\begin{tabular}{|c|c|c|c|c|c|c|}
\hline \multicolumn{7}{|c|}{$\begin{array}{l}\text { Journal of Economics and Behavioral Studies (ISSN: 2220-6140) } \\
\text { Vol. 11, No. 4, pp. 88-101, August } 2019 \\
\end{array}$} \\
\hline \multirow{3}{*}{ Competition } & No competition & 112 & 18027.68 & 16181.02 & 1500 & 90000 \\
\hline & Competition & 231 & 16373.16 & 11560.49 & 500 & 80000 \\
\hline & Total & 343 & & & & \\
\hline \multirow[t]{3}{*}{ Seasonoper } & $\begin{array}{l}\text { Demand for the product isn't } \\
\text { seasonal }\end{array}$ & 108 & 18323.15 & 16762.88 & 2000 & 90000 \\
\hline & Demand is seasonal & 235 & 16265.53 & 11252.31 & 500 & 80000 \\
\hline & Total & 343 & & & & \\
\hline \multirow{5}{*}{ SocNet } & Not in both edir and ekub & 28 & 11967.86 & 14673.86 & 2000 & 78000 \\
\hline & In ekub only & 145 & 14946.9 & 9436.97 & 800 & 45000 \\
\hline & In Edir only & 33 & 17430.3 & 9841.858 & 500 & 45000 \\
\hline & In both Edir and ekub & 137 & 19881.02 & 16226.59 & 1500 & 90000 \\
\hline & Total & 343 & & & & \\
\hline
\end{tabular}

Source: Own computation from survey data, 2018

\section{Empirical Analysis}

Estimation Methods: Maximum Likelihood Estimators: In table 6 all three models support that there is technical inefficiency in our model. The value of lamda $(\lambda)$ is also greater than 1 the three cases which consolidate the significance of inefficiency. The value of gamma $(\gamma)$ also shows that a $95.6 \%$ variation in output is because of technical inefficiency. This validates that output among enterprises in the sample might vary because of technical inefficiency. Thus, we use Maximum Likelihood Estimates (MLE) because it provides appropriate results. Table 6 indicates that explanatory variables of production function are all together highly significant which is confirmed by the generalized likelihood ratio test. The null hypothesis: $\eta 1=\eta 2=\eta 3=0$ is rejected at $1 \%$ level of significance.

Table 6: Maximum Likelihood Estimates of the Cobb Douglas Stochastic Production Frontier Function with the Various Distribution of Inefficiency Term

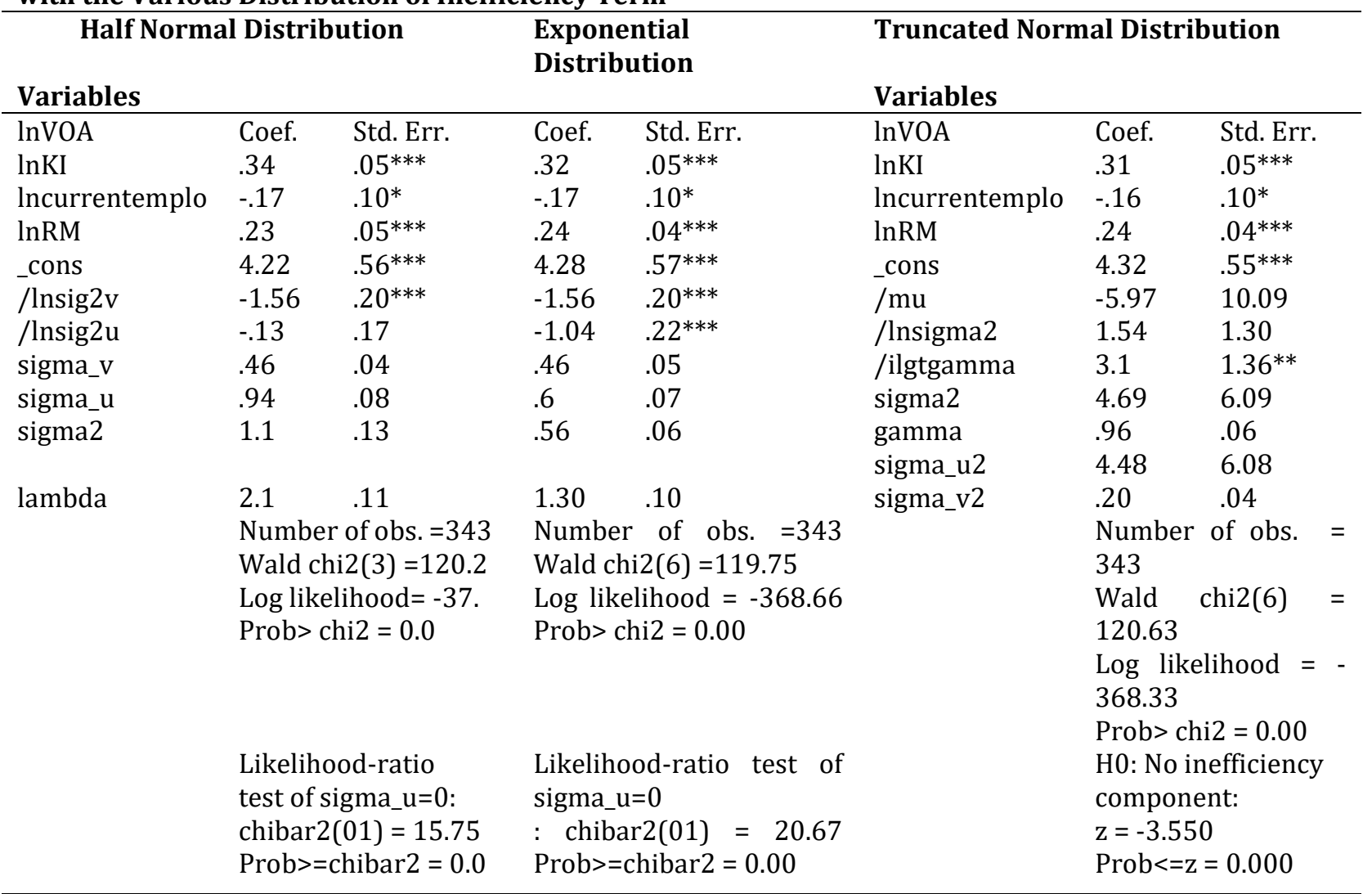

***, ${ }^{* *}$ and ${ }^{*}=$ significant at $1 \%, 5 \%$ and $10 \%$ respectively 
The impact of only labor input on VOA is opposite to what was expected and significant at $10 \%$. On average as capital input and raw materials increases by $1 \%$ output value-added increases by about $0.3 \%$ and $0.2 \%$ respectively, other things remaining constant. On the other hand, as labor input increases by $1 \%$ output value-added decreased by about $0.2 \%$ on average, other things remaining constant. The coefficients of the input variables suggest that MSMEs experienced decreasing returns to scale. The sum of the coefficients of the inputs is 0.4. In this study, we used a single-stage maximum likelihood model because of its advantages (i.e. it does not violate the distributional assumption of the error terms).

Table 7: Maximum Likelihood Estimates of the Stochastic Production Frontier and Inefficiency Effect Models with Various Distribution of Inefficiency Term

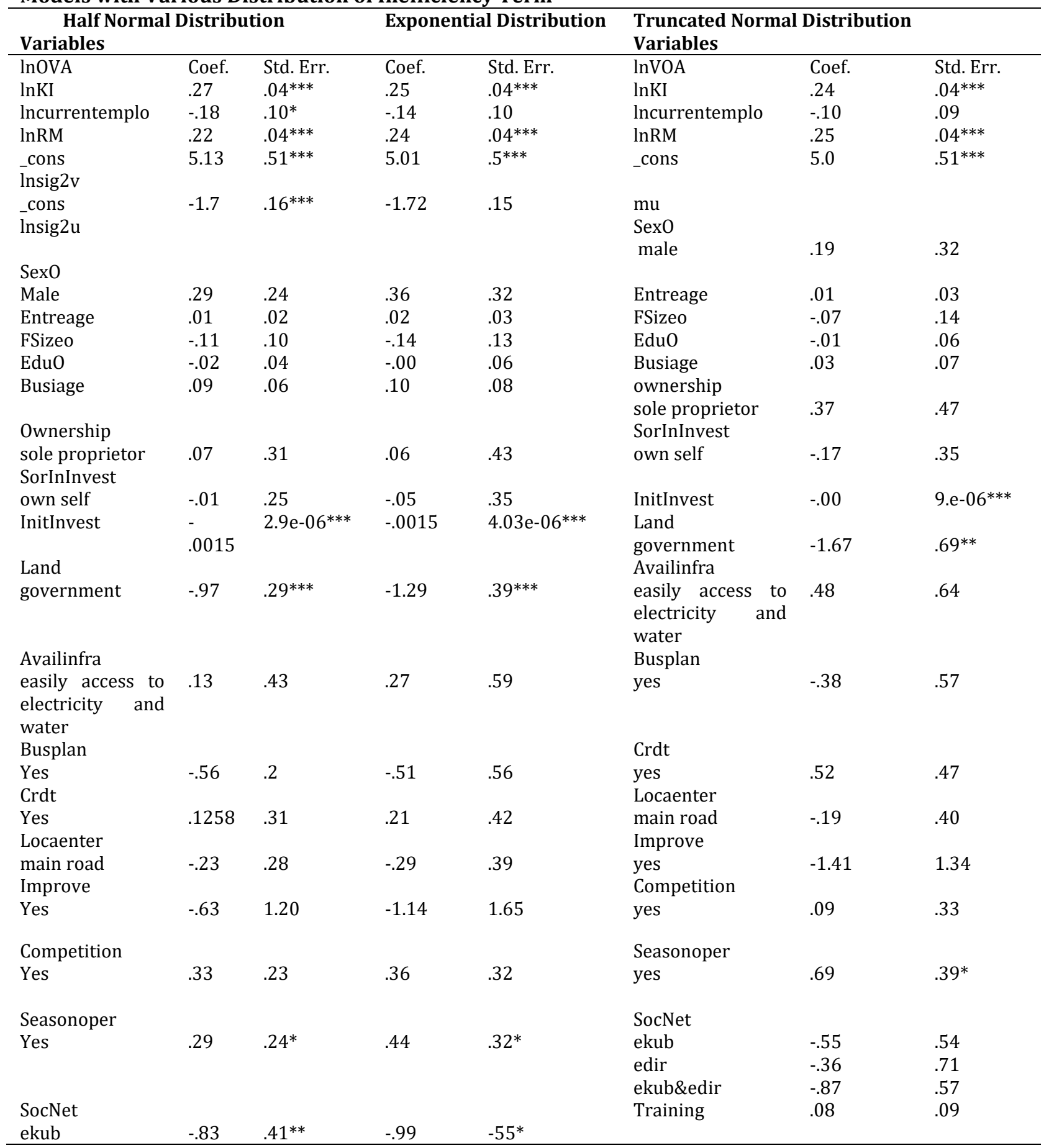




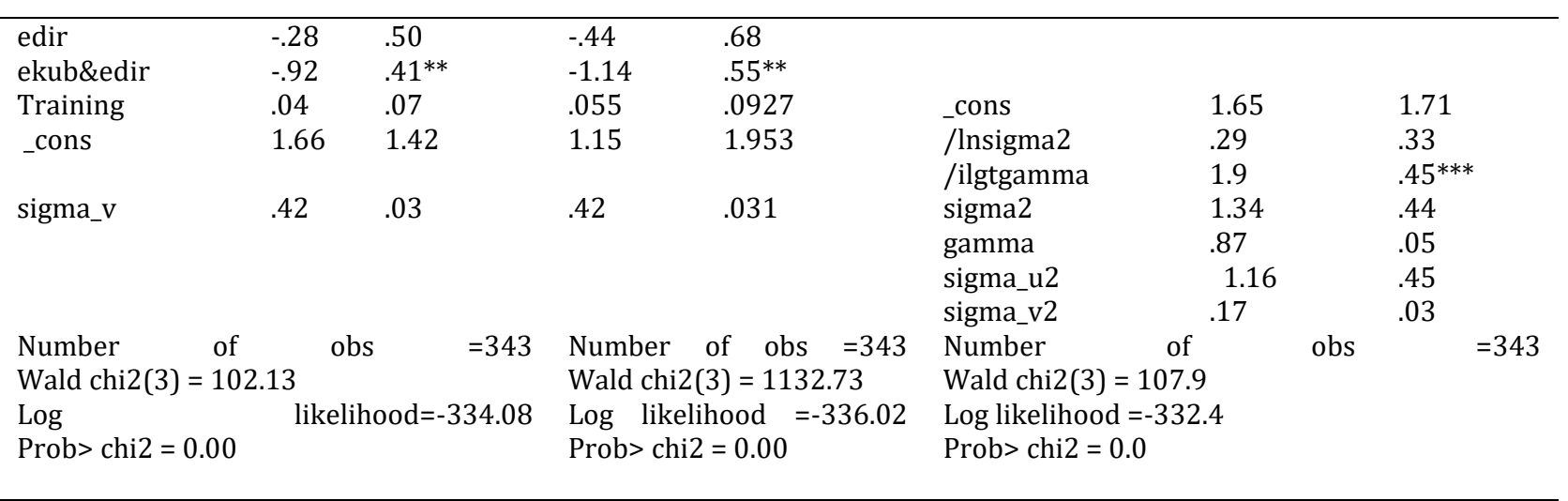

$*, * *$ and ${ }^{* * *}=$ significant at $10 \%, 5 \%$ and $1 \%$ level of significance respectively

Table 8 indicates the result from the combined estimation of stochastic production function and technical inefficiency effects in all three models. The value of the generalized log-likelihood test indicates that all variables are jointly significant that is:

$H_{o}: \eta 1=\eta 2=\eta 3=0$ in the case of stochastic production frontier and

$H_{o}: \eta 1=\eta 2=\eta 3=\eta 4=\eta 5=\eta 6=\eta 8=\eta 9=\eta 10=\eta 11=\eta 12=\eta 13=\eta 14=\eta 15=\eta 16=\eta 17=\eta 18=\eta 19=\eta 20=\eta 21=0$ in the case of inefficiency effect model, is rejected at $1 \%$ level of significance. One can understand from table 8 that capital input and raw material are significant in all three types of distribution while labor input has no impact on value added output in case of exponential and truncated distribution when stochastic frontier and inefficiency effects are estimated in combination, other things being constant. This indicates that there is a room to increase output value-added (estimated as monthly sales value) by increasing the amount of capital input and raw material, but not labor input. From the independent variables included in technical efficiency model only five variables (i.e. InitInvest, government Land, Seasonoper, Ekub, both Ekub and Edir) are found statistically significant in both half normal and exponential.

While only three variables (InitInvest, government land and seasonal demand for product) are statistically significant in case of truncated normal distribution. Other things being constant, on average as money available for initial investment expense increases by one percent, the technical inefficiency of enterprises decreases by about $0.0015 \%$ and it is statistically highly significant at $1 \%$ level significance. This is because the larger the money available to finance the expenses of enterprises, the easier to run enterprises smoothly. The enterprises can purchase their raw materials without difficulty and run their business more efficiently, citrus paribus. Other things being constant, the technical inefficiency of those enterprises which received land from government decreases by 0.97 as compared to the enterprises which received land from other bodies (rented/own land) and it is statistically highly significant at $1 \%$ level significance. This might be an incentive to produce efficiently as others are discouraged by rent expenses paid (if the land is rented from other) or imputed income lost from their own land used for enterprise operation. As compared to those enterprises which do participate neither in "Ekub" nor "Edir", the technical inefficiency of those enterprises which participate in Ekub decreases by 0.83 on average and it is statistically significant at $5 \%$ level significance, citrus paribus. This might be because of developing social capital and sharing information and knowledge when they meet each other.

Furthermore, they might be encouraged to produce efficiently so that they can cover their commitment to the group and save more to ease financial difficulties. It is also found that the technical inefficiency of those who participate in both "Ekub" and "Edir" decreases on average by 0.92 as compared to those enterprises which do participate in neither "Ekub" nor "Edir" and it is statistically significant at 5\% level significance. This might be because of the reason similar to "Ekub", but wider than it. It means that those enterprises which participate in both "Ekub" and "Edir" are exposed to larger group and commitment so that they are more efficient. The technical inefficiency of enterprises of which the demand for their product changes seasonally increases by 0.3 as compared to those enterprises of which the demand for their product does not change seasonally and it is statistically significant at 5\% level significance. This might be because they are discouraged by the market they lost during the low season. Table 8 presents the estimate of mean efficiency 
of sampled enterprises which is about $54.8 \%$ with a minimum $5 \%$ and a maximum $89.99 \%$. This shows that enterprises are not producing the possible maximum output from their inputs with presently applied technology. One can understand that there is a great gap (45.2\%) to raise their output without raising their input on average. The inefficiency score $(45.2 \%)$ shows sampled enterprises are not using their inputs efficiently.

Table 8: Estimate of Technical Efficiency

\begin{tabular}{llllll}
\hline \multirow{3}{*}{ Technical Efficiency } & Obs. & Mean & Std. Err. & Min. & Max. \\
\cline { 2 - 7 } & 343 & .548 & .1813597 & .0514058 & .8998769 \\
\hline
\end{tabular}

One can see from table 9 that none of the sampled enterprises achieved greater than $90 \%$ efficiency score and one sampled enterprises achieved less than $10 \%$ of efficiency score.

Table 9: Frequency Distribution of Technical Efficiency for Individual Enterprises

\begin{tabular}{lllll}
\hline Efficiency Interval & Frequency & Cumulative Frequency & Percentage & $\begin{array}{l}\text { Cumulative } \\
\text { Percentage }\end{array}$ \\
\hline $\mathrm{TE}<0.1$ & 1 & 1 & 0.3 & 0.3 \\
$0.1<\mathrm{TE}<0.2$ & 18 & 19 & 5.2 & 5.5 \\
$0.2<\mathrm{TE}<0.3$ & 37 & 56 & 10.78 & 16.28 \\
$0.3<\mathrm{TE}<0.4$ & 19 & 75 & 5.54 & 21.82 \\
$0.4<\mathrm{TE}<0.5$ & 19 & 94 & 5.54 & 27.36 \\
$0.5<\mathrm{TE}<0.6$ & 81 & 175 & 23.62 & 50.98 \\
$0.6<\mathrm{TE}<0.7$ & 109 & 284 & 31.78 & 82.76 \\
$0.7<\mathrm{TE}<0.8$ & 46 & 330 & 13.41 & 96.17 \\
$0.8<\mathrm{TE}<0.9$ & 13 & 343 & 3.8 & 100 \\
$0.9<\mathrm{TE}<1$ & 0 & 343 & 0 & 100 \\
\hline
\end{tabular}

Kernel Density Estimation for the Half-Normal Distributional Assumption: To separate error component (stochastic) and inefficiency effects in the model, a distributional assumption has to be made for $u_{i}$, Coelli (1996). Among many empirical works on technical efficiency study, some of them like Battese and Coelli (1996); Coelli (1996); Aigner et al. (1977) show us that technical efficiency can only be estimated if inefficiency effects error term, are stochastic and has a non-negative truncation with truncated normal distributional specification. Accordingly, to check, a kernel density function is drawn in the stata version 13 in Figure 2.

Figure 2: kernel Density

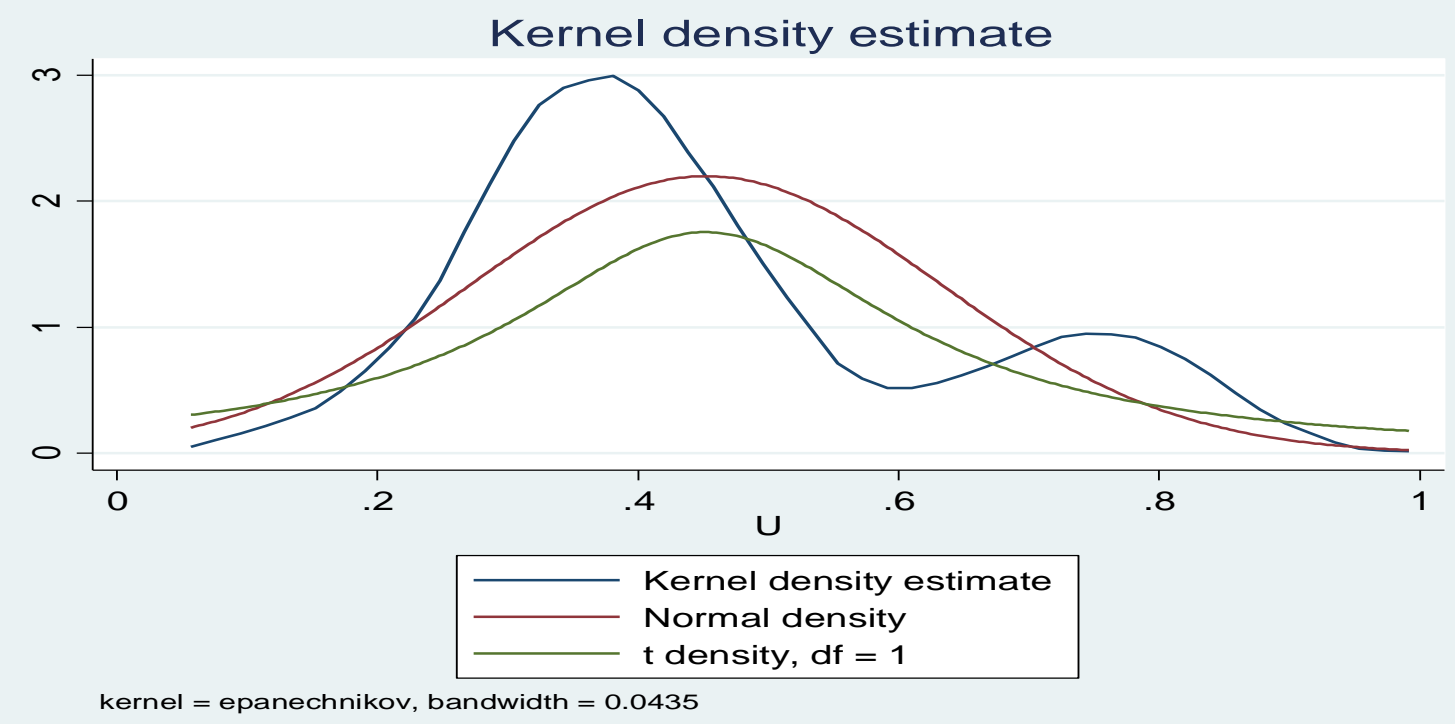




\section{Conclusion and Recommendations}

Conclusion: In recent decade Ethiopian government set an objective to the rapid structural transformation of the economy (i.e. from Agriculture led economy to industry-led economy). To achieve this objective various policy programs were formulated specifically focusing on Micro and Small-Scale Enterprises so that they are the base for industrial development. However, the rate by which Micro and small-scale manufacturing enterprises have been growing is slower than that of large and medium scale manufacturing industries over the last decade. Besides, previous studies show that the greatest number of Micro and Small-Scale Enterprises are unable to grow and are survival type which cannot provide new employment opportunities. Thus, the researchers are motivated to find out factors that change the level of technical efficiency of Micro and Smallscale Manufacturing Enterprises and recommend appropriate policy action based on finding. The finding from stochastic production frontier shows that output value-added is positively affected by capital input and raw material, but negatively affected by labor inputs used in production.

The finding from the inefficiency model shows that technical inefficiency: is negatively affected by the amount of finance used for initial investment expense; lower for enterprises which received land from the government, participate only in "Ekub", participate in both "Ekub" and "Edir". However, seasonal change in demand for the product is found to make technical inefficiency of enterprises higher. Furthermore, the result from the inefficiency model indicates that the sampled enterprises can increase output value-added by simply improving their technical efficiency. Since the mean of technical efficiency of sampled enterprises is $54.8 \%$ substantial increment in output value-added can be made regardless of increment in current amount of resources and improvement in technology used. To test the specification of the model and reliability of results, some tests were conducted. The non-stochastic inefficiency hypothesis with a null hypothesis that the standard deviation of $u$ equals zero is strongly rejected at $1 \%$ level of significance in all models (i.e. halfnormal distribution, exponential distribution and truncated distribution models). The null hypothesis of no skewness is also rejected at $1 \%$ level of significance which supports for a left-skewed error distribution.

Recommendations: The finding of the study identified major factors influencing technical efficiency of Micro and Small-scale Manufacturing Enterprises in selected towns of Jimma zone. Based on the finding of the study the following recommendations are forwarded:

$\checkmark \quad$ It is found in the study that technical inefficiency is lower for enterprises that get land from the government during their startup. Thus, the concerned officials should encourage MSEs by providing land used for the operation of enterprises.

$\checkmark \quad$ The study also found that seasonal change in demand for the product makes technical inefficiency of enterprises higher. Thus, Food Security and Job creation office as well as Trade and Industry office should facilitate market accessibility for the MSEs by linking them with potential demanders of their product/s.

$\checkmark$ It is also found in the study that higher startup capital leads to the higher efficiency of MSEs. Thus, the concerned office should facilitate access of MSEs to sufficient startup capital.

$\checkmark$ Finally, we recommend that MSEs should strength their social capital by participating in "Ekub" and/or "Edir" since it is found in the study that technical efficiency is higher for those who participate in "Ekub", both "Ekub" and "Edir".

Acknowledgements: First of all, we want to extend our deepest gratitude to Jimma University for the research grant. Next, our appreciation goes to Jimma Zone and Jimma City office of food security and job creation as well as office of trade and industry, and micro and small-scale enterprise offices of the sampled towns for their genuine cooperation during the data collection process. Finally, we are indebted to the data collectors for their authentic way of collecting the primary data in all of the sampled towns. 


\section{References}

Aigner, D. C., Lovell, K. \& Schmidt, P. (1977). Formulation and estimation of stochastic frontier production function models, Journal of Econometrics, (6), 21-37.

Amare, A. E. \& Raghurama, A. (2017). Micro, Small and Medium Enterprises (MSMEs) Development Strategies in Ethiopia: Retrospective and Prospective Analysis. IRACST - International Journal of Commerce, Business and Management (IJCBM), 6.

Berihu, A., Abebaw, Z. \& Biruk, T. (2014). Identifying Key Success Factors and Constraints in Ethiopia's Mse Development: An Exploratory Research. Ethiopian Development Research Institute Addis Ababa, Ethiopia October 2014

Cochran, W. G. (1977). Sampling techniques (3rd ed.). New York: John Wiley \& Sons.

Coelli, T. J. (1996). A Computer Program for Stochastic Frontier Production and Cost Function Estimation center for Efficiency and Productivity Analysis (CEPA) Australia.

CSA. (2007). Population and Housing Census of 2007 Ethiopia

Donald, C. M. \& Carl, L. (1998). The Dynamics of Micro and Small Enterprises in Developing Countries. World Development, 26(1), 6I-74.

EEA. (2015). Small and Micro Enterprises (SMEs) Development in Ethiopia: Policies, Performances, Constraints and Prospects. EEA Research Brief Issue, 5.

Erkoc, T. E. (2012). Estimation Methodology of Economic Efficiency: Stochastic Frontier Analysis vs. Data Envelopment Analysis. International Journal of Academic Research in Economics and Management Sciences, 1(1).

Essien, A. E. \& Yakub, A. B. (2007). Technical efficiency of small and medium scale industries (SMI) in Nigeria: evidence from nation-wide sample survey. Studia universitatis Babes-Bolyai, Negotia, Lii, 2.

Farrell, M. J. (1957). The measurement of productive efficiency. Journal of the Royal Statistical Society, 120(3), 253-290.

FDRE. (2016). Growth and Transformation Plan II (GTP II) Volume I: Main Text. National Planning Commission May, 2016 Addis Ababa.

Gamachis, G. (2017). Productivity of MSEs: DEA Approach. International Journal of Scientific and Research Publications, 1.

Gebreyesus, M. (2007). Growth of micro-enterprises: Empirical evidence from Ethiopia.

Hinderink, J. \& Titus, M. (2002). Small towns and regional development: Major findings and policy implications from comparative research. Urban studies, 39(3), 379-391.

Igbekele, A. A. \& Adebiye, G. D. (2003). Efficiency of microenterprises in the Nigerian economy. AERC Research Paper 134 African Economic Research Consortium, Nairobi September 2003

Mosomi, J. N. Y. (2011). Technical Efficiency of Micro and Small Enterprises in Kenya. Research Paper Submitted in Partial Fulfillment of the Requirements of the degree of Master of Arts in Economics of the University of Nairobi.

Rajesh, R. S. N. (2007). Technical Efficiency in the Informal Manufacturing Enterprises: Firm level evidence from an Indian state. MPRA, Munich Personal RePEc Archive.

Tekle, L., Sandraa, R. \& Berhanu, K. (2016). Determinant of Technical Efficiencies of Micro and Small Enterprises in Wolaita Zone, Ethiopia. Journal of Economics and Sustainable Development, 7(21).

Wasihun, R. \& Paul, I. (2010). Growth determinants of women operated micro and small enterprises in Addis Ababa. Journal of Sustainable Development in Africa, 12(6), 233-246.

William, H. G. (2008). The econometric approach to efficiency analysis. Oxford University press.

Zulridah, M. N. \& Liew, Ch. S. (2014). Technical Efficiency of Malaysian Manufacturing Small and Medium Enterprises, 676-688. 